\title{
Analisis Pemetaan Kerentanan Masyarakat Terhadap Bencana Gempa: Studi Kasus Gempa di Haiti Tahun 2010
}

\author{
Jusmalia Oktaviani*, jusmalia.oktaviani@lecturer.unjani.ac.id \\ Christy Pavita Kumesan*, christy.kumesan@gmail.com \\ Saltiq Fajar*, saltiqfajar@hotmail.com
}

\begin{abstract}
Abstrak
Haiti terletak di Pulau Hispaniola, yang merupakan perbatasan antara lempeng tektonik Amerika dan Karibia. Lempeng ini bergerak sekitar 2 sentimeter per tahun, sehingga termasuk seismik aktif dan memiliki sejarah gempa yang panjang. Namun, dengan sejarahnya yang sering terkena gempa, tidak membuat negara ini menjadi siap terhadap gempa. Pada tahun 2010, gempa yang cukup besar, dengan skala sekitar 7 SR menerpa Haiti. Korban jiwa yang diakibatkan oleh gempa tersebut mencapai 100.000 hingga 300.000 jiwa. Menurut UN General Assembly, kerugian total akibat gempa bumi diperkirakan mencapai USD 7.8 milyar, yang berarti setara dengan lebih dari 120 persen GDP Haiti di tahun 2009. Melalui tulisan ini, peneliti ingin mengetahui bagaimana analisis kerentanan masyarakat Haiti terhadap bencana alam, terutama gempa, karena dengan skala yang sebenarnya tidak terlalu besar (7 SR), gempa tahun 2010 tersebut menelan begitu banyak korban jiwa. Penelitian ini menggunakan metode penelitian kualitatif dengan teknik pengumpulan data documentary analysis. Penelitian ini menunjukkan bahwa bencana alam mempunyai beberapa dimensi, dan membutuhkan penanganan komprehensif agar jumlah korban jiwa akibat gempa bisa ditekan dan diminimalisir oleh pemerintah.
\end{abstract}

Kata Kunci: bencana alam, gempa, kerentanan masyarakat.

\begin{abstract}
Haiti is located on the island of Hispaniola, which is the border between America and Caribbean tectonic plates. These plates move about 2 centimeters per year, thus including seismically active, has a long history of earthquakes. However, as a land which often affected by the earthquake, this state is not ready against earthquakes. In 2010, an earthquake, about 7 SR scale hit Haiti. The loss of life caused by the earthquake reached 100,000 to 300,000. According to the UN General Assembly, a total loss due to the earthquake is estimated at USD 7.8 billion, which would be equivalent to more than 120 percent of Haiti's GDP in 2009. By this article, the researchers probe the Haiti's community vulnerability analysis towards natural disasters, particularly earthquakes, because the actual scale of the earthquake itself is not enormous, only 7 SR of 10 SR, however the earthquake in 2010 swallowed so many losses. This study uses qualitative research methods with data collection techniques documentary analysis. The result shows that a natural disaster has several dimensions, and requires a comprehensive action so that the number of casualties caused by the earthquake can be suppressed and minimized by the government.
\end{abstract}

Keywords: natural disasters, earthquakes, community vulnerability

\footnotetext{
* Korespondensi: Prodi Hubungan Internasional, Universitas Jenderal Ahmad Yani, Jalan Terusan Jenderal Sudirman PO BOX 148, Cimahi.

* Korespondensi: Alumnus Program Pascasarjana Hubungan Internasional UGM, Konsentrasi Diplomasi Humaniter Global.

* Korespondensi: Alumnus Program Pascasarjana Hubungan Internasional UGM, Konsentrasi Diplomasi Humaniter Global.
} 


\section{Pendahuluan}

Pada tanggal 12 Januari 2010, gempa bumi dengan kekuatan 7 Skala Richter mengguncang Haiti dengan pusat gempa $16 \mathrm{~km}$ dari Port-au-Prince pada pukul 4:53:09 waktu lokal (21:53:09 UTC). Pusat gempa berada pada kedalaman $10 \mathrm{~km}$. Gempa bumi ini juga dirasakan di Teluk Guantánamo, Kuba, Kingston, Jamaika, Caracas, Venezuela, Santo Domingo, dan Republik Dominika. Gempa bumi di Haiti menyebabkan kerusakan di kota-kota di Haiti seperti Port-au-Prince, Leogane, Gressier, Grand Goave, Petit Goave, dan Jacmel di Timur Selatan. Gempa berpengaruh pada sektor penting, khususnya bidang sosial, produksi dan infrastruktur. Perkiraan jumlah korban tewas bervariasi, berkisar dari 100.000 hingga 316.000 (World Vision Australia, 2010). Pemerintah Haiti memperkirakan bahwa 250.000 tempat tinggal dan 30.000 bangunan komersial runtuh atau rusak berat (Renois, 2010).

Gambar 1. Pusat Gempa Haiti tanggal 12 Januari 2010, kurang lebih 16 km dari ibukota Haiti, Port-au-Prince

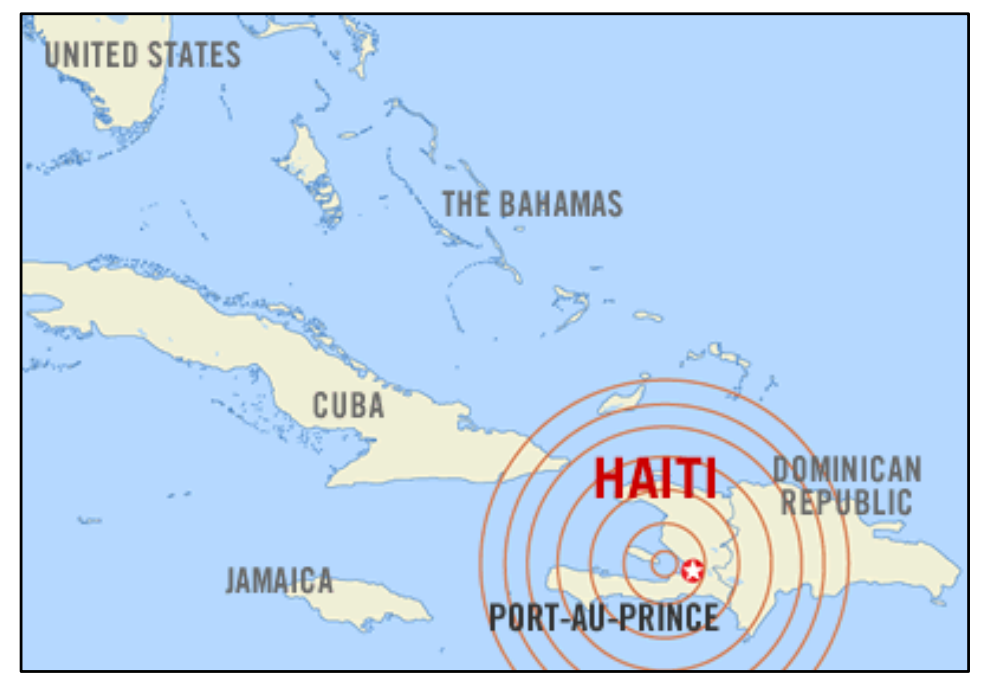

Sumber : http://www.elon.edu/images/e-web/news/haitimap.gif

Haiti merupakan negara yang tidak asing dengan bencana alam. Selain gempa bumi, negara ini juga sering dilanda badai tropis, yang menyebabkan banjir dan kerusakan yang luas. UNDP (2009) menyebutkan, Haiti termasuk negara miskin dengan peringkat 149 dari 182 negara dalam Indeks Pembangunan Manusia (Human Development Index). Sementara itu, menurut FAO atau Food and Agriculture Organization, 
Haiti disebut sebagai negara dengan 'economically vulnerable' atau rentan secara ekonomi (dalam Renois, 2010). Dengan skala yang tidak terlalu tinggi, yakni 7 SR, kehilangan korban jiwa dan materi yang ditimbulkan oleh bencana ini begitu besar. Dilihat dari begitu besarnya dampak dan kerusakan yang terjadi di Haiti saat mengalami gempa tahun 2010, maka tulisan ini bertujuan untuk menganalisis hal-hal yang membuat negara Haiti menjadi rentan/vulnerable terutama terhadap gempa bumi pada tahun 2010 tersebut.

\section{Metode Penelitian}

Penelitian ini adalah penelitian kualitatif. Menurut Lexy J. Moleong (2008:6) penelitian kualitatif yakni penelitian yang bermaksud untuk memahami fenomena tentang apa yang dialami oleh subjek penelitian misalnya perilaku, persepsi, motivasi, tindakan dan lain-lain, secara holistik, dan dengan cara deskripsi dalam bentuk kata-kata dan bahasa, pada suatu konteks khusus yang alamiah dan dengan memanfaatkan berbagai metode alamiah. Dalam mengumpulkan data, penelitian ini menggunakan documentary analysis atau analisis dokumen karena metode pengumpulan data yang digunakan dalam penelitian ini berbentuk dokumentasi, baik untuk memahami isinya secara substansi atau untuk menjelaskan makna yang lebih dalam dari dokumen-dokumen tersebut. Bahan dokumenter berbentuk buku atau catatan harian, laporan dari media, surat resmi, otobiografi, surat-surat pribadi, memorial, kliping, dokumen pemerintah atau swasta, data di website, dan seterusnya (Hammersley dan Atkinson (1995) dalam Ritchie, 2003: 35; Rahmat, 2009:7).

\section{Kerangka Konseptual}

Bankoff et al (2004: 133-134) dalam Mapping Vulnerability Disasters, Development and People menyatakan setidaknya terdapat tiga macam pandangan dan strategi pencapaian dalam menunjukkan kerentanan, yaitu 1) alam sebagai penyebab; 2) biaya sebagai penyebab; 3) struktur sosial sebagai penyebab. Tiga pandangan Bankoff tersebut akan dijelaskan lebih rinci sebagai berikut:

\section{Alam sebagai penyebab (Nature as cause)}

Pandangan ini menghadirkan ilmu pengetahuan dan teknologi (IPTEK) sebagai solusi. Dalam pandangan ini, alam dan bencana alam dipandang sebagai sebab 
dari kerentanan manusia terhadap bencana, yang berfluktuasi berdasarkan intensitas, magnitud, serta durasi dari peristiwa eksternal. Kerentanan merupakan hasil dari bahaya (termasuk intensitas) dan resiko (paparan peristiwa, yang diukur berdasarkan aspek kedekatan/proksimal). Agar dapat mengurangi kerentanan tersebut, diperlukan sistem untuk dapat memprediksi datangnya bahaya dan rancangan serta pengaplikasian teknologi yang memungkinkan manusia untuk bertahan dari dampak negatif suatu bencana (alat untuk memonitor aktivitas gempa bumi, ramalan cuaca, memonitor kekeringan dan kebakaran menggunakan teknik remote sensing, sistem pengontrol air, serta keamanan bangunan).

\section{Biaya sebagai penyebab (Cost as cause)}

Pandangan ini berfokus pada solusi dalam aspek ekonomi dan keuangan. Meskipun kapasitas IPTEK sudah ditingkatkan dan diperbaiki, namun manusia terkadang masih mengalami penderitaan karena teknologi mitigasi dan prediksi bencana memakan biaya yang besar. Para ahli ekonomi mengembangkan dan memperbaiki metode untuk menilai besarnya kerugian yang diderita akibat bencana agar dapat melakukan penghitungan tentang apakah, kapan, bagaimana dan di mana pengurangan kerentanan dapat berjalan dan diterapkan. Dalam pandangan ini, kerentanan akan berkurang apabila pemerintah domestik menyesuaikan jaring pengaman sosial yang aman, dana untuk bencana dan asuransi jiwa, serta menyediakan bantuan keuangan untuk meningkatkan aset penduduk (World Bank, 2001:135).

\section{Struktur sosial sebagai penyebab (Societal Structure as cause)}

Pandangan ini menawarkan politik sebagai solusi dari permasalahan yang terjadi. Dalam pandangan ini memperlihatkan bahwa bencana memiliki dampak turunan terhadap masyarakat yang tinggal di wilayah-wilayah yang rawan bencana. Bukan hanya terpapar akan bahaya dari ancaman bencana tersebut, namun proses sosio-ekonomi dan politik dalam lingkungan masyarakat juga mendorong tereksposnya kerentanan. Hal demikian menciptakan kondisi yang secara berlawanan mempengaruhi kemampuan masyarakat atau negara dalam merespons situasi bencana, serta untuk mengatasi dan pulih dari efek destruktif suatu bencana. Kondisi demikian mendahului peristiwa bencana, berkontribusi pada kepelikan atau memperparah bencana tersebut dan bahkan dapat tetap berlangsung pada fase paska bencana (Anderson dan Woodrow, 1989; Blaikie et al, 1994). 
Menurut F. Cuny (1983) dalam Disaster and Development, mengurangi kerentanan masyarakat miskin merupakan suatu pertanyaan yang jawabannya terdapat pada politik. Dalam persepsi demikian, kondisi lingkungan yang lebih aman hanya dapat dicapai apabila respons terhadap bencana mengubah rangkaian proses yang menyebabkan manusia ada dalam situasi bahaya. Solusi jangka panjang terletak pada transformasi struktur sosial dan politik yang memelihara kemiskinan dan dinamika serta perilaku sosial yang melestarikan kemiskinan tersebut (Heijmans dan Victoria, 2001).

\section{Analisis dan Pembahasan}

Melalui teori yang dikemukakan oleh Bankoff, maka peneliti mencoba untuk menganalisis mengenai kerentanan Haiti terhadap gempa pada tahun 2010 melalui tiga pendekatan penyebab kerentanan, yakni alam, biaya, dan struktur sosial.

\section{Alam sebagai penyebab (Nature as cause)}

Haiti dan Republik Dominika merupakan pulau Hispaniola yang terletak persis di sebelah geological fault zone yang disebut oleh para peneliti sebagai 'a major seismic hazard bagi para penduduknya. Dalam Inside Disaster, Michael Blanpied dari U.S. Geological Survey (USGS) menjelaskan bahwa Hispaniola terperangkap di antara dua lapisan tektonik yang 'mencukur, menghancurkan, dan menggerinda pulau ini'. Ini membuat kemungkinan gempa lebih dari 5 skala ritcher akan sering terjadi di Haiti. Oleh karena itulah Haiti sangat rentan terhadap bahaya gempa bumi.

Gempa yang terjadi pada tanggal 12 Januari 2010 adalah salah satu contoh gempa terparah yang terjadi di negara tersebut. Gempa saat itu sebesar 7.0 skala Richter, dengan pusat gempa 15 mil dari barat daya kota Port-au-Prince. Pada gempa yang cukup besar, gempa susulan secara alami akan mengguncang daerah tersebut dengan kekuatan yang semakin lama semakin menurun. Faktor gempa susulan ini menyebabkan penduduk Haiti terhadap gempa bumi semakin tinggi karena lereng curam dan terjal yang berada di dekat pusat gempa meningkatkan peluang untuk gempa dan gempa susulan yang dipicu oleh tanah longsor, yang menimbulkan bahaya lebih lanjut untuk struktur tanah serta masyarakat sekitar (Margesson, 2010: 1).

Kenyataannya di Haiti sendiri, ketika itu tercatat sekitar 14 gempa susulan dengan skala lebih dari 5.0 SR masih mengguncang Haiti dan juga terjadi 36 gempa 
dengan skala di atas 4.0 SR yang dirasakan oleh penduduk hanya dalam jangka waktu 24 jam pasca gempa besar terjadi. Akibatnya, kerusakan yang terjadi pada kota-kota di negara Haiti pun semakin parah, karena gempa susulan dengan skala yang masih cukup besat masih mengguncang kota tersebut (Margesson, 2010:3). Selain itu, pusat gempa juga dekat dengan kota yang memiliki kepadatan penduduk tinggi, seperti Port-auPrince, Leogane dan Jacmel, menjadikan gempa 2010 tersebut sebagai gempa yang banyak mengakibatkan korban jiwa serta menjadikannya gempa yang paling kuat yang pernah dialami oleh negara itu selama 200 tahun terakhir (Rencoret, 2010:7).

\section{Biaya sebagai penyebab (Cost as Cause)}

\section{a. Ketidaksiapan Pemerintah dalam Penanggulangan Pasca Bencana}

Ketidaksiapan pemerintah dalam menghadapi bencana terlihat dari 'disaster after disaster', di mana banyaknya angka kematian juga diakibatkan oleh kondisi di lapangan pasca bencana gempa. Gempa bumi berkekuatan masif tersebut menghancurkan sistem perairan di Petit Goave yang berjarak sekitar $68 \mathrm{~km}$ dari ibukota, Port-au-Prince. Sehingga, korban yang selamat dari bencana kesulitan mendapatkan akses air bersih.

Bukan hanya itu, krisis yang terjadi di Haiti pasca gempa bumi yakni berupa wabah kolera serta kebutuhan yang sangat kritis terhadap akses layanan kesehatan, air dan sanitasi, pendidikan serta perlindungan dan keamanan. Hingga tahun 2014 terdapat 58.608 kasus kolera di seluruh Haiti, di mana 601 orang telah meninggal di tahun 2013 saja. Selain itu 600.000 orang masih hidup dalam kelaparan. Tiga belas komune di Haiti masih dalam situasi krisis pangan dan 106 komune dalam status 'food stress'. Malnutrisi yang terjadi pada balita meningkat dari 5,1\% di tahun 2012 menjadi 6,5\% di tahun 2013. Sekitar 100.000 balita terdeteksi mengidap malnutrisi dan 20.000 balita lainnya menderita malnutrisi akut (Relief Web, 2014). Hal ini menunjukkan betapa rentannya kehidupan rakyat Haiti pasca gempa.

\section{b. Mahalnya Biaya untuk Mendirikan Bangunan Tahan Gempa}

Haiti berbeda dari negara lain yang berada di wilayah lempeng tektonik yang rawan gempa, di mana negara-negara yang berada di wilayah rawan gempa pasti memiliki kode membangun yang aman dari gempa. Namun karena sebagian besar masyarakat Haiti hidup di bawah garis kemiskinan, mereka tidak memiliki pengetahuan 
dan dana yang cukup untuk membangun suatu bangunan yang baik dan aman dari bencana. Sebuah bangunan yang tahan gempa membutuhkan biaya 10-20\% lebih banyak dari bangunan biasa. Bagi jutaan penduduk Haiti yang berpenghasilan di bawah $\$ 2$ perhari tentu tidak mampu membangun rumah yang tahan gempa (Inside Disaster, 2014). Hal ini seperti yang dikatakan oleh Cletus Springer, direktur dari Department of Sustainable Development, Organization of American States, "The poverty in Haiti lends itself to people building where they want, how they can ... not everybody's going to be able to build to the exacting standards that a building code requires." Bangunan yang tidak kuat ini menjadi jebakan maut bagi jutaan penduduk Haiti jika bangunan tersebut runtuh karena gempa. Ahli gempa Ian Main mengatakan, "The buildings were brittle and had no flexibility, breaking catastrophically when the earthquake struck" (Inside Disaster, 2014).

\section{c. Kerentanan Geologis dan Tata Kota}

Sebagai wilayah yang rentan terhadap bencana, maka kerentanan terhadap gempa bumi seharusnya menjadi bagian dari perencanaan tata kota dan negara. Wilayah geologi tertentu (daerah-daerah tertentu di mana ada batu kapur di Port-au-Prince dan daerah-daerah tertentu di mana ada jalur patahan) secara teoritis lebih berisiko daripada yang lain. Bahkan dua kota terbesar Haiti, yakni Port-au-Prince dan Cap Haitian tepat terletak di atas jalur patahan. Hal seperti ini sebenarnya dapat diidentifikasi sehingga peraturan bangunan dan perencanaan yang lebih spesifik dan terbatas dapat diterapkan. Masalah tata kota ini belum diperhatikan oleh pemerintah. Kepadatan penduduk juga berpengaruh terhadap kerentanan masyarakat Haiti itu sendiri. Kepadatan penduduk di kota-kota tertentu di Haiti membuat angka kematian melonjak karena banyaknya masyarakat yang langsung terkena dampak bencana gempa. Rural Poverty Portal menyebutkan, pada tahun 2010, dari 10 juta penduduk Haiti, terdapat 5,1 juta orang yang tinggal di kota dengan kepadatan penduduk 362,6 orang per km persegi.

\section{d. Masalah Arsitektural}

Perubahan bahan rumah dari kayu ke batu dan kemudian beton, dengan tidak adanya standar tahan gempa, membuat gempa bumi lebih mematikan. Sebagian besar dari penduduk yang tewas dalam gempa bumi justru adalah mereka yang tinggal di gedung-gedung batu dan beton, karena konstruksi kayu lebih fleksibel dan lebih tahan terhadap jenis tekanan yang dihasilkan oleh gerakan kerak bumi. Tapi karena harga kayu lebih mahal dan pengalihan model budaya di perumahan, secara tidak 
langsung semen dan beton blok telah menjadi 'norma' sejak awal 60-an. Semua bangunan yang dibangun sejak saat itu terbuat dari beton. Perubahan tersebut membuat rumah-rumah beton dipandang sebagai tanda kekayaan dan kemakmuran. Masalahnya tidak semua rumah-rumah itu dibangun sesuai dengan standar. Para kontraktor di Haiti biasanya menggunakan bahan bangunan yang murah dan pondasi yang lemah untuk membangun perumahan di Haiti. Tidak adanya kode membangun di wilayah rawan bencana dan ditambah lagi dengan minimnya kontraktor berlisensi, teknisi dan arsitektur yang berkontribusi dalam pembangunan membuat penduduk Haiti sangat rentan terhadap bencana terutama gempa. Bangunan yang lemah membuat orang yang tinggal di dalamnya pun sangat rentan menjadi korban jika guncangan besar seperti gempa terjadi. Karena rendahnya standar struktur bangunan di Haiti membuat korban yang jatuh ketika gempa 2010 sangat besar karena tertimpa runtuhan rumah mereka sendiri.

Rendahnya standar bangunan di Haiti ditunjukkan dengan dibatasinya panjang batang baja tulangan, membatasi jumlah "beton penuh" dan meningkatkan persentase pasir yang digunakan. Daerah-daerah seperti Paco dan di sekitar Champs de Mars dan bagian dari Bourdon dan Delmas dibuat lebih rapuh. Dengan alasan menghemat biaya, perumahan-perumahan yang vertikal pun dibuat dengan standar rendah. Norma-norma dan aturan tahan gempa tidak diperhitungkan dan pemotongan biaya pada beton mengurangi kemampuan bangunan untuk menahan getaran. Pada akhirnya, daerah termiskin seperti kota-kota kumuh Cité Soleil dan Martissant, gubukgubuk yang dibangun di daerah tersebut justru hanya menderita kerusakan kecil (Georges dan Grünewald, 2014).

\section{Struktur Sosial Sebagai Penyebab (Societal Structure as Cause)}

\section{a. Struktur Sosial dan Kemiskinan}

Vulnerability yang diderita oleh rakyat Haiti juga dapat kita lihat dari struktur sosial yang ada di dalam masyarakatnya. Walaupun Haiti sudah merdeka dari penjajahan Prancis pada 1 Januari 1804 dan menjadi negara yang dipimpin oleh ras Negroid pertama di dunia, tetapi struktur sosial di Haiti masih sangat dipengaruhi sistem sosial pada masa kolonial. Pada masa kolonial struktur sosial di Haiti dibagi menjadi 3 kelas, yaitu di puncak kelas adalah elit putih (grands blancs), kelas menengah 
adalah freedmen (affranchis), dan kelas terbawah adalah budak hitam (noirs) (Mongabay, 2014). Pada masa kolonial orang-orang kulit putih (grands blancs) yang menguasai Haiti dan menjadi kaum elit, di mana mereka mengatur dan menguasai perpolitikan, ekonomi dan juga sosial budaya. Orang-orang kulit hitam (noirs) merupakan budak yang dipekerjakan oleh pemerintah kolonial. Diantara elit kulit putih dan budak kulit hitam terdapat kelas menengah yang adalah keturunan budak yang sudah merdeka dan juga mulato (campuran kulit hitam dan kulit putih). Kelas menengah ini boleh memiliki tanah sehingga perekonomian mereka sudah cukup baik. Sebanyak 19.000 orang dari seluruh jumlah penduduk Haiti pada tahun 1791, 87 persen merupakan budak, 8 persen merupakan elit kulit putih, dan 5 persen merupakan freedmen (Mongabay, 2014).

Setelah masa kemerdekaan struktur sosial mengalami perubahan di mana yang berada pada kelas teratas adalah urban elit dan pemimpin militer. Orang-orang yang berada pada kelas teratas ini hanya sebanyak 2 persen dari total penduduk Haiti tetapi merekalah yang mengontrol lebih dari $44 \%$ pendapatan nasional negara. Kelas menengah Haiti merupakan orang-orang mulato yang duduk di dalam pemerintahan. Kemudian ada kelas petani yang merupakan $75 \%$ dari total jumlah penduduk Haiti. Para petani ini inilah yang menjadi tulang punggung negara karena pendapatan utama dari Haiti adalah dari sektor agrikultur. Tetapi walaupun mereka memberikan pendapatan paling banyak bagi negara, mereka hidup di bawah garis kemiskinan karena tanah yang mereka garap bukanlah tanah mereka. Hal ini dikarenakan sebagian besar tanah di Haiti hanya dimiliki oleh orang-orang yang berada di kelas teratas. Diperkirakan $3 / 4$ warga Haiti tinggal di tanah yang bukan milik mereka sehingga mereka harus menyewa (Inside Disaster, 2014). Kelas terbawah adalah urban lower class yang merupakan warga miskin yang hidup di kota-kota besar di Haiti. Kelas ini semakin meningkat dengan semakin besarnya jumlah warga yang berpindah dari desa ke kota untuk mencari hidup yang lebih baik.

Lebih lanjut, struktur sosial yang ada di Haiti memperlihatkan bahwa hanya sebagian kecil orang saja yang menikmati kekayaan sumber daya alam Haiti, sementara sebagian besar dari rakyat Haiti hidup di bawah garis kemiskinan. Data CIA menunjukkan bahwa 80\% rakyat Haiti hidup di bawah garis kemiskinan, di mana 54 persennya hidup dalam abject poverty. Seperti yang kita ketahui rakyat yang hidup dalam kemiskinan inilah yang paling rentan terhadap bencana. Kemiskinan yang terjadi di 
Haiti membuat mereka tidak bisa melindungi diri mereka sendiri ketika bencana alam terjadi, sehingga ketika gempa bumi terjadi pada tahun 2010 korban yang jatuh pun sangat banyak. Struktur sosial yang tidak adil membuat mereka semakin terekspos pada bencana.

\section{b. Urbanisasi dan Kepadatan Penduduk}

Struktur sosial masyarakat di Haiti yang tidak adil seperti penjelasan sebelumnya mendorong perubahan pada struktur masyarakat Haiti. Untuk mendapatkan hidup yang lebih baik, banyak rakyat Haiti yang memilih untuk pindah ke kota atau melakukan urbanisasi. Urbanisasi besar-besaran yang dilakukan oleh rakyat Haiti dilakukan pada tahun 1989 di mana dari 6,1 juta total jumlah penduduk Haiti 75\% tinggal di kota-kota besar di Haiti dan 25\% sisanya yang tinggal di desa, di mana kepadatan penduduknya sebesar 182 orang per km persegi (Mongabay, 2014). Berdasarkan data dari Rural Poverty Portal, hal ini semakin meningkat di tahun 2010 di mana dari total 10 juta total penduduk Haiti, 5,1 juta orang tinggal di kota dengan kepadatan penduduk 362,6 orang per $\mathrm{km}$ persegi. Hal ini menunjukkan terjadi peningkatan 2 kali lipat jumlah penduduk yang tinggal di kota. Kepadatan penduduk yang terjadi di dekat pusat gempa pada tahun 2010 membuat lebih setengah dari jumlah penduduk Haiti terkena dampak langsung dari gempa. Sebagian besar rakyat yang terkena dampak gempa di Port-au-Prince merupakan rakyat yang tinggal di perkampungan-perkampungan miskin di kota, sehingga membuat mereka semakin rentan karena minimnya infrastruktur dan struktur tempat tinggal yang jauh dari pantas. Hal ini juga yang kemudian membuat korban jiwa yang jatuh pada saat gempa pun semakin besar.

\section{c. Instabilitas Politik dan Pemerintahan}

Sepanjang sejarah Haiti berdiri sebagai negara merdeka, Haiti dipenuhi oleh ketidakstabilan politik di mana Haiti pernah diperintah secara otoriter. Setelah mengalami pemberontakan bersenjata yang berujung pada pengunduran diri secara paksa dan pengasingan presiden Jean-Bertrand Aristide pada tahun 2004, pemerintah sementara kemudian mengambil alih pemerintahan dan juga mempersiapkan pemilu di bawah pangawasan PBB. Selama masa pemerintahan sementara ini pun terjadi ketidakstabilan dan pemilu ditunda dikarenakan alasan teknis. Tetapi akhirnya Haiti berhasil memilih presiden dan parlemen secara demokratis pada tahun 2006. Pemilu 
baru bisa diadakan pada tahun 2010 yang kemudian memenangkan presiden Michel Martelly. Tetapi pemerintahan Haiti dikenal korup dan tingginya tingkat kemiskinan membuat pemerintahan tidak dapat berjalan dengan baik. Ketika terjadi gempa tahun 2010 membuat vulnerability rakyat Haiti semakin terlihat. Pada saat gempa terjadi pemerintahan Haiti benar-benar lumpuh total sehingga rakyatnya semakin menderita karena tidak ada respons yang cepat dari pemerintah. Salah satu korban mengatakan, "Nobody is coming, I think only God is in charge. The government should be here, any government. There is no government in the palace right now. I don't even really know if Haiti has a government today." (McClatchy Newspapers and The New York Times, 2014) Hal ini memperlihatkan betapa tidak tanggapnya pemerintah Haiti terhadap bencana yang menimpa negaranya.

Dengan lemahnya posisi pemerintah, rakyat Haiti juga akan semakin rentan terhadap bencana alam. Lemahnya pemerintahan juga akan berdampak pada proses rekonstruksi dan pembangunan di Haiti yang berjalan sangat lamban. Selain masalah endemik kolera yang memakan banyak korban jiwa, masalah pengungsi juga belum terselesaikan. Hingga tahun 2014 setelah 4 tahun berlalu masih banyak rakyat Haiti yang masih belum mendapat bantuan. Hingga akhir 2013, masih terdapat sekitar 172.000 pengungsi domestik (IDPs) yang tersebar di 306 kamp penampungan. Sekitar 16.000 IDP beresiko mengalami pengusiran dari masyarakat lokal. Sementara itu, sekitar 80.000 IDPs tinggal di tempat penampungan yang rawan akan banjir serta lingkungan yang tidak mendukung.

Permasalahan pengungsi mempengaruhi kondisi sosial budaya masyarakat Haiti di mana kebanyakan pengungsi berasal dari wilayah-wilayah yang sangat miskin. Menurut The Brookings Institution dalam Disasters, Development, and Durable Solutions (2014), penekanan terhadap pemerintah serta donor untuk menyadari bahwa permasalahan IDPs dan resolusinya bukan sekedar permasalahan kemanusiaan, namun juga merupakan proses pembangunan yang membutuhkan investasi jangka panjang. Dalam situasi seperti yang terjadi di Haiti, diperlukan adanya peningkatan hubungan kerja sama dan dukungan lintas sektor agar mencapai solusi yang lebih memiliki tingkat durabilitas yang baik. 


\section{d. Kurangnya Partisipasi Masyarakat}

Untuk negara yang sangat rentan terhadap risiko bencana seperti Haiti, kemampuan warga untuk memberikan pertolongan pertama dengan cepat dan untuk mengambil tindakan yang tepat sangat penting (Georges dan Grünewald, 2014) Kemampuan pertolongan pertama untuk menyelamatkan nyawa di menit pertama atau jam pertama setelah bencana pasti akan menyelamatkan banyak nyawa. Sangat sedikit orang yang mengetahui cara melakukan pertolongan pertama di Haiti. Hal ini harusnya menjadi salah satu faktor kunci dari strategi manajemen risiko nasional negara Haiti.

Bukan hanya masalah pemberian pertolongan pertama, kurangnya partisipasi dari masyarakat saat bencana terjadi membuat keadaan masyarakat di Haiti semakin memburuk pasca bencana. Hal ini dibuktikan oleh evaluasi yang dilakukan oleh USAID's Haiti Transition Initiative yang menyatakan bahwa ketika gempa terjadi, masyarakat, khususnya masyarakat kota di Haiti, cenderung bergantung pada pemerintah kota untuk menyelesaikan semua masalah. Masyarakat tidak berusaha untuk saling membantu atau setidaknya menyelesaikan masalah mereka sendiri. Hal ini salah satunya diakibatkan oleh perubahan struktur masyarakat karena urbanisasi yang dilakukan oleh masyarakat desa ke kota. Para warga yang hidup di kota dan biasanya berstatus sebagai pendatang tidak memiliki keluarga, teman, atau jaringan seperti saat masih di desa. Hal ini menyebabkan support system seseorang ketika berada di kota otomatis berkurang. Perpindahan yang dilakukan tersebut secara tidak langsung telah memutus orang-orang dari jaringan atau dukungan komunitas lokal (masyarakat desa) yang lebih saling membantu satu sama lain karena kedekatan antaranggota masyarakatnya (Rencoret, 2010: 17).

\section{Kesimpulan}

Bencana alam seperti gempa bumi merupakan bencana yang sulit diramalkan kedatangannya oleh manusia, apalagi untuk menghentikan getaran bumi dan gerakan jalur patahan tektonik sehingga tidak terjadi gempa. Aktivitas tektonik juga merupakan hal yang lumrah terjadi karena pergerakan lempeng bumi yang memang bergerak secara perlahan. Tapi dengan pengetahuan yang semakin lama semakin berkembang, manusia bisa membatasi dampak atau kerusakan yang terjadi pasca 
pergerakan kerak bumi tersebut, sehingga gempa bumi tidak harus selalu mematikan setiap kali terjadi.

Kerentanan manusia terhadap bencana salah satunya bisa dilihat dari tiga pandangan di atas, yakni melihat alam sebagai penyebab, biaya sebagai penyebab, atau struktur sosial sebagai penyebab. Ketiga pandangan tersebut sebenarnya tidak eksklusif satu sama lain, atau dengan kata lain, ketiganya sebenarnya saling berhubungan. Namun, aktor kemanusiaan seringkali hanya memandang kerentanan dari pandangan pertama dan kedua, sehingga manusia seringkali dilihat sebagai korban (pasif), bukan sebagai aktor yang aktif serta memiliki pengaruh dan peran dalam hal kebencanaan dan pencegahannya. Kerentanan manusia terhadap bencana juga dianggap sebagai masalah yang bersifat 'seasonal/musiman'. Padahal masalah struktur sosial dan ekonomi yang tidak adil bisa berdampak pada kerentanan masyarakat terhadap bencana semenjak sebelum, selama, dan sesudah bencana itu terjadi.

Haiti adalah negara yang sangat rentan terhadap bencana, bahkan jauh sebelum gempa 12 Januari 2010. Melalui gempa Haiti, ada aspek-aspek kerentanan yang sebenarnya bisa dihindari agar di masa depan tidak ada lagi jatuhnya korban jiwa yang tidak perlu. Gempa bumi memang bencana yang tidak bisa diperkirakan dan dicegah, namun mengurangi kerentanan masyarakat terhadap gempa bumi bukan berarti tidak mungkin dilaksanakan. Salah satu cara mengurangi kerentanan tersebut adalah daerah beresiko dari gempa bumi seperti tanah yang curam dan terjal harus dipetakan, norma-norma dan aturan dalam konstruksi harus didirikan dan dihormati, informasi harus tersedia, dan kesadaran harus ditingkatkan di antara masyarakat tentang bahaya yang ada di sekitar mereka, dan sebagainya. Cara-cara untuk mengurangi kerentanan tersebut adalah intervensi yang bisa dilakukan manusia pada aspek kedua dan ketiga, yakni biaya dan struktur sosial sebagai penyebab.

Hasil penelitian di atas menunjukkan, faktor pertama, yakni alam sebagai penyebab, justru tidak banyak menyumbang dalam tingginya tingkat kematian di Haiti. Banyak faktor yang mempengaruhi tingginya jumlah kematian pada gempa Haiti tahun 2010, justru berasal dari faktor 'manusia', seperti kemiskinan, tidak adanya standar bangunan pembangunan di daerah beresiko gempa bumi dan banjir, kepadatan penduduk yang tinggi di daerah-daerah tertentu, kurangnya infrastruktur, perencanaan tata kota yang buruk, kurangnya sosialisasi terhadap masyarakat mengenai pertolongan 
pertama dan lain-lain. Hal tersebut di atas memberikan kontribusi untuk menciptakan kerentanan terhadap aspek "sosio-natural" bencana, sebuah konsep yang menunjukkan bahwa peristiwa alam hanya menjadi bencana ketika bencana itu mempengaruhi masyarakat yang tidak siap menghadapinya. Selain itu, sangat penting bagi pemerintah pusat, pemerintah lokal, dan komunitas atau LSM di Haiti memiliki pola koordinasi yang baik dan terstruktur, terutama karena negara itu termasuk ke dalam wilayah rawan bencana.

Dengan teori yang sama, penelitian lanjutan bisa dilakukan di daerah rawan bencana lain, seperti Indonesia. Penelitian tentang kebencanaan perlu terus dilakukan, agar masyarakat tidak mudah menyalahkan 'alam' sebagai faktor penyebab utama dalam hilangnya korban jiwa, tanpa melihat pada kesalahan manusia itu sendiri sebagai kontributor terbesar dalam bencana alam.

\section{Daftar Rujukan}

\section{Buku}

Anderson, M \% Woodrow P. (1989). Rising from the Ashes: Development Strategies in Times of Disasters. London: Westview Press.

Bankoff, G.. et. al. (Eds). (2004). Mapping Vulnerability: Disasters, Development and People. London: Earthscan.

Blaikie, P., et. al. (1994). At Risk: Natural Hazards, People's V ulnerability, and Disasters (2nd Edition). London: Routledge.

Cuny, F. (1983). Disasters and Development. Oxford: Oxford University Press.

Heijmans, A \& Victoria L. (2001). Citizenry-Based and Development-Oriented Disaster Response: Experience and Practise in Disaster Management of the Citizens' Disaster Response Networks in the Philippines. Manila: Center for Disaster Preparedness.

Moleong, L. J. (2008). Metode Penelitian Kualitatif. Bandung: Remaja Rosda Karya.

World Bank. (2000). World Development Report 2000/2001: Attacking Poverty. New York: Oxford University Press.

\section{Jurnal}

Rahmat, P. S. (2014) “Penelitian Kualitatif.” Equilibrium 5.9 (Jan-Juni 2009): 1-8. Rilis 30 November 2014 pada http://yusuf.staff.ub.ac.id/files/2012/11/JurnalPenelitian-Kualitatif.pdf. 
Ritchie, Jane. (2003). "The Applications of Qualitative Methods to Social Research". Qualitative Research Practice: A Guide for Social Science Students and Researchers. Eds. Jane Ritchie dan Jane Lewis. London, Thousand Oaks, New Delhi: Sage Publications, 2003. 24-46.

\section{Artikel Online}

World Vision Australia. (2010). "A Call to Action: Haiti at 6 months", World Vision Australia (12 July 2010). Diakses pada 05/04/2014.

CIA. (n.d.). "The World Factbook: Haiti”. Diakses 5 April 2014, pada https://www.cia.gov/library/publications/the-worldfactbook/geos/ha.html

Reliefweb. (2010). "Disaster". Diakses 04/04/2014 Pukul 19.00 WIB, pada http://reliefweb.int/disaster/eq-2010-000009-hti

USGS.(2010). 'Earthquakes'. Diakses 04/04/2014 Pukul 19.00 WIB, pada http://earthquake.usgs.gov/earthquakes/eqinthenews/2010/us2010rja6 /\#summary

Georges, Y. \& François G. (2010). “Haiti's vulnerability to earthquakes: the case for a historical perspective and a better analysis of risks". Diakses 04/04/2014 pukul 15.30 WIB, pada http://www.urd.org/Haiti-s-vulnerability-to

Inside Disaster. (n.d.). “Why Was the Destruction So Severe?”. Diakses 5 April 2014 http://insidedisaster.com/haiti/the-quake/why-was-the-destruction-sosevere

Inside Disaster. (n.d.). “The Haiti Earthquake: Transformations”. Diakses 5 April 2014, pada http://insidedisaster.com/haiti/recovery/transformations

McClatchy Newspapers and The New York Times. "With Haiti's government in ruins, 'only God is in charge'". Diakses pada 5 April 2014, pada http://seattletimes.com/html/nationworld/2010808076_haiticontrol16. html

Margesson, R. \& Maureen T. M. (2010). "Haiti Earthquake: Crisis and Response." Congressional Research Service diakses pada 15 Februari 2017. 
Mongabay. (n.d.). "Haiti-Society". Diakses pada 4 April 2014, pada http://www.mongabay.com/reference/country_studies/haiti/SOCIET Y.html.

Relief Web. (2014). "Haiti: Humanitarian Dashboard. Diakses 5 April 2014, pada http://reliefweb.int/report/haiti/haiti-humanitarian-dashboard-6february-2014-enfr

Rencoret, N. et al. (2010). "Haiti Earthquake Response: Context Analysis.” ALNAP Secretariat. Diakses pada 15 Februari 2017.

Renois, C. (2010). "Fears of major catastrophe as 7.0 quake rocks Haiti". Agence France-Presse. Archived from the original on 15 January 2010. Diakses tanggal 05/04/2014.

Rural Poverty Portal. (2010). "Haiti: Statistics". Diakses 5 April 2014, pada http://www.ruralpovertyportal.org/en/country/statistics/tags/haiti

The Brookings Institution. (2010). "Disasters, Development, And Durable Solutions To Displacement: Insights From Haiti”. Diakses 4 April 2014, pada http://reliefweb.int/sites/reliefweb.int/files/resources/20140314_haiti_ development_transcript.pdf

Unicef USA. (2010). “Haiti Earthquake.” Diakses 4 April 2014, pada http://www.unicefusa.org/work/emergencies/Haiti/ 